Marquette University

\title{
e-Publications@Marquette
}

College of Nursing Faculty Research and

Publications

Nursing, College of

$1-2016$

\section{Translating Research to Practice for Children With Autism Spectrum Disorder: Part I: Definition, Associated Behaviors, Prevalence, Diagnostic Process, and Interventions}

Norah L. Johnson

Marquette University, norah.johnson@marquette.edu

Karen Burkett

Cincinnati Children's Hospital Medical Center

Judy Reinhold

Cincinnati Children's Hospital Medical Center

Margaret W. Bultas

Saint Louis University

Follow this and additional works at: https://epublications.marquette.edu/nursing_fac

Part of the Nursing Commons

Recommended Citation

Johnson, Norah L.; Burkett, Karen; Reinhold, Judy; and Bultas, Margaret W., "Translating Research to Practice for Children With Autism Spectrum Disorder: Part I: Definition, Associated Behaviors, Prevalence, Diagnostic Process, and Interventions" (2016). College of Nursing Faculty Research and Publications.

425.

https://epublications.marquette.edu/nursing_fac/425 
Marquette University

e-Publications@Marquette

\section{Nursing Faculty Research and Publications/College of Nursing}

This paper is NOT THE PUBLISHED VERSION; but the author's final, peer-reviewed manuscript. The published version may be accessed by following the link in the citation below.

Journal of Pediatric Health Care, Vol. 30, No. 1 (January-February 2016): 15-26. DOI. This article is (C) Elsevier and permission has been granted for this version to appear in e-Publications@Marquette. Elsevier does not grant permission for this article to be further copied/distributed or hosted elsewhere without the express permission from Elsevier.

\section{Translating Research to Practice for Children with Autism Spectrum Disorder: Part I: Definition, Associated Behaviors, Prevalence, Diagnostic Process, and Interventions}

Norah L. Johnson

Assistant Professor, College of Nursing, Marquette University, Milwaukee, WI

Karen Burkett

Pediatric Nurse Practitioner, Division of Developmental and Behavioral Pediatrics, APN Faculty Leadership Education in Neurodevelopmental Disabilities (LEND), Cincinnati Children's Hospital Medical Center, Cincinnati, $\mathrm{OH}$

Judy Reinhold

Pediatric Nurse Practitioner, The Kelly O'Leary Center for ASDs, Division of Developmental and Behavioral Pediatrics, Cincinnati Children's Hospital Medical Center, Cincinnati, $\mathrm{OH}$

Margaret W. Bultas

Assistant Professor, School of Nursing, Saint Louis University, St. Louis, MO 


\section{Abstract}

\section{Introduction}

The number of children with autism spectrum disorder (ASD) is rising, along with the potential for challenging behaviors during health care encounters.

\section{Method}

We present an overview of the emerging science related to ASD diagnosis and interventions for children with ASD.

\section{Results}

Emerging science on ASD reveals common associated challenging behaviors, increasing prevalence, emphasis on early diagnosis at 18 to 24 months of age, changes in the diagnostic process with criteria from the Diagnostic and Statistical Manual of Mental Disorders, 5th edition, and interventions with medication, education, and behavior management.

\section{Discussion}

Family and health care provider preparation strategies facilitate care of children with ASD and their families. Early diagnosis at 18 to 24 months of age and evidence-based interventions contribute to best outcomes for children and families. Health care providers must be aware of the state of the science for diagnosis and best practices to provide family-centered care for this growing population.

\section{Key Words}

Autism spectrum disorder, autism, ASD, diagnosis, behavior

Autism spectrum disorder (ASD) is a developmental disorder that presents with atypical language and social behavior, along with restrictive and repetitive behaviors and unusual interests (American Psychiatric Association [APA], 2013). The spectrum of behaviors and their severity are highly variable (Hall, 2012). The behaviors may be self-inflicted (e.g., hitting or biting oneself) and/or externalized (e.g., hitting or kicking others; Johnson, Bekhet, Robinson, \& Rodriguez, 2014; Matson et al., 2011). Behaviors may be exacerbated when children are stressed, such as in health care settings (Hall, 2012, Johnson and Rodriguez, 2013, Johnson et al., 2014, Matson et al., 2011).

Discerning the most accurate information about ASD to use as a basis for recommendations for familycentered ASD treatment can be challenging for nurse practitioners and other health care practitioners (HCPs), given the complexity of the symptoms and wide range of presentation (Lounds Taylor et al., 2012, Warren et al., 2011). The objective of this review article is to describe the evidence for the HCP's role in screening, the diagnostic process, and interventions with children who have ASD. We present background on the current state of the science related to ASD definition, associated behaviors, prevalence, the diagnostic process, and interventions. 


\section{ASD Definition}

The definition of ASD has developed over time since it was introduced in the third edition of the Diagnostic and Statistical Manual of Mental Disorders (DSM-III; American Psychiatric Association [APA], 1980). Prior to 1980, ASD symptoms were considered to be representative of early onset schizophrenia (American Psychiatric Association, 1952, American Psychiatric Association, 1968). The fourth revision of the DSM categorized the symptoms of ASD into three distinct pervasive developmental disorders (PDDs): autism, PPD-not otherwise specified, and Asperger syndrome (APA, 1994). The classification of the PDDs did not change with the DSM IV-text revision (APA, 2000). With the fifth edition of the DSM, the three PDDs are collapsed into one diagnostic disorder, ASD. The diagnosis of Asperger syndrome and PDD-not otherwise specified are no longer given in the DSM-5. Future prevalence studies may be affected, given the change in the categorization of ASD with the DSM-5 (Swineford, Thurm, Baird, Wetherby, \& Swedo, 2014).

The new DSM-5 diagnostic disorder ASD has two main criteria: (A) persistent social communication and social interaction deficits and (B) restricted, repetitive patterns of behavior, interests, or activities (see Box 1). A child may demonstrate all of the A criteria as early as age 2 years if the child does not respond to his or her name, has no or limited joint attention, and shows a lack of reciprocal interaction. An example of the B criteria in a toddler is an unusually strong interest in a play telephone during which time he does not engage with his mother, respond to his name, or share enjoyment with his mother about the phone. Adherence to restricted routines can lead to difficulties with transitions and challenging behaviors, such as tantrums (Weitlauf et al., 2014).

Box 1

Criteria for diagnosis of autism spectrum disorder ${ }^{a}$

Criteria A: Persistent social communication and social interaction deficits in multiple contexts. Includes deficits in all three areas:

- Social-emotional reciprocity.

- Nonverbal communicative behaviors used for social interaction.

- Developing, maintaining, and understanding relationships.

Criteria B: Restricted, repetitive patterns of behavior, interests, or activities. Includes at least two:

- Stereotyped or repetitive movements, use of objects, or speech.

- Insistence on sameness, inflexible adherence to routines, or ritualized patterns of verbal or nonverbal behavior.

- Highly restricted, fixated interests that are abnormal in intensity or focus.

- Hyper- or hyporeactivity to sensory input or unusual sensory environment interest.

Criteria C: Symptoms were present in early developmental period.

Criteria D: Symptoms correlate with clinically significant impairments in social or occupational functioning.

Criteria E: Impairments are not better explained by intellectual disability or global developmental delay.

Clinician specifies the following:

- With or without intellectual impairment. 
- With or without language impairment.

- Any associated or known medical or genetic condition.

- Any associated neurodevelopmental, mental or behavioral disorder.

Severity rating:

Level 1: Requires support.

Level 2: Requires substantial support.

Level 3: Requires very substantial support.

Note. adapted criteria for Autism Spectrum Disorder in the Diagnostic and Statistical Manual for Mental Disorders, edition 5 (American Psychiatric Association, 2013).

The DSM-5 also requires clinicians to specify other diagnoses that may be present, such as cognitive or language impairment, known medical or genetic conditions, and other neurodevelopmental or behavior disorders (APA, 2013). The clinician rates the severity of the ASD on three levels. Level 1 requires support; level 2 requires substantial support; and level 3 requires very substantial support (APA, 2013).

\section{Associated Behaviors}

Challenging behaviors that accompany ASD are sometimes very difficult for families to manage. A variety of behaviors are associated with ASD. For example, aggression and self-injury have a significant impact on quality of life for children and families on the autism spectrum (Johnson, Frenn, Feetham, \& Simpson, 2011). Anxiety is often seen to be a trigger for these behaviors (Davis et al., 2011). The anxiety can be linked to both receptive and expressive communication skill deficits that accompany ASD (Davis et al., 2010). Children with ASD also may have obsessive-compulsive features or the need for predictability and sameness. These characteristics can lead to some stressful situations for families (Miles, 2011).

\section{Prevalence of ASD}

Based on DSM-IV criteria, the prevalence of ASD in the United States is estimated to have increased from 1 in 10,000 people in the 1990s (Rutter, 2007) to 1 in 68 people (about 4.7 million) in 2014, with a 4:1 male to female prevalence (Baio et al., 2014). The broadening of the concept of autism in the DSMIV to include Asperger syndrome increased the supports for ASD and the diagnostic surveillance in health and educational care. It also improved ASD awareness, which helps explain the increasing ASD prevalence (Baio et al., 2014, Fombonne, 2009, Rutter, 2007).

Some of the symptoms of ASD are subtle and therefore difficult to recognize on a consistent basis, which complicates the HCP's ability to recognize the earliest signs of ASD.

Some of the symptoms of ASD are subtle and therefore difficult to recognize on a consistent basis, which complicates the HCP's ability to recognize the earliest signs of ASD. This subtlety can add another layer of diagnostic uncertainty for the clinician working with the culturally diverse child. Although the ASD phenotype (i.e., how the child looks and behaves) does not differ by culture, the prevalence of ASD among diverse cultural groups differs significantly. White children have a $30 \%$ 
greater prevalence for being diagnosed with ASD than African American children and a 50\% greater prevalence than Hispanic children (Baio et al., 2014).

African American and Hispanic children are diagnosed with ASD on average 2.5 to 2.6 years later than White children (Kerfeld et al., 2011, Mandell et al., 2002, Mandell et al., 2009, Valicenti-McDermott et al., 2012). When African American and Hispanic children are diagnosed later, their ASD symptoms can be more severe, including poorer social reciprocity or the risk for an intellectual disability (Baio et al., 2014, Jarquin et al., 2011). Additionally, African American children with ASD are more often misdiagnosed with a behavioral disorder such as attention deficit hyperactivity disorder, adjustment disorder, or conduct disorder than are White children (Mandell, Ittenbach, Levy, \& Pinto-Martin, 2007).

Lags in obtaining the ASD diagnoses for African American and Hispanic children can lead to preventable delays in implementing interventions to improve outcomes (Burkett, Morris, Manning-Courtney, Anthony, \& Shambley-Ebron, 2015). These preventable delays represent a health care disparity in the United States. Multiple cultural factors contribute to lack of early diagnosis and lack of timely interventions for African American and Hispanic children with ASD, including (a) HCP diagnostic bias of the White male child, whose prevalence of diagnosis with ASD is typically higher than that of other ethnicities; (b) poorer health care accessibility than White children; (c) uncertainties about the presenting symptoms of African American and Hispanic children; and (d) family understanding of ASD symptoms (Mandell et al., 2007). When HCPs offer diagnostic and intervention care to families of culturally diverse backgrounds based on knowledge and understanding of these cultural factors, there exists a greater potential for reducing the gap of health care disparities for African American and Hispanic children with ASD (Burkett and Morris, 2015, Zuckerman et al., 2014).

\section{The Diagnostic Process}

\section{Early Identification of ASD}

Identification of ASD as early as 18 to 24 months of age is imperative so HCPs can direct families of children with ASD to evidence-based treatments for the best child and family outcomes (Weitlauf et al., 2014). Multiple studies have shown the effectiveness of early and intensive treatments on child outcomes in ASD (Dawson et al., 2010, Weitlauf et al., 2014). In response to this urgent need to recognize the signs of ASD early in a child's life, the Centers for Disease Control and Prevention (CDC) developed the "Learn the Signs Act Early" campaign, including a booklet listing normal child developmental milestones (Daniel, Prue, Taylor, Thomas, \& Scales, 2009). An element of the campaign is the development and distribution of "Milestones booklets" that list the normal child developmental milestones. These booklets are available as a free download on the CDC Web site (http://www.cdc.gov/ncbddd/actearly/freematerials.html). To date, no research studies are available in the medical literature with regard to the effectiveness of this campaign.

The CDC also provides training video clips of the key early indicators of a risk for ASD to assist clinicians in the diagnostic process. The Learn the Signs Act Early Curriculum: Autism Case Training Videos (http://www.cdc.gov/NCBDDD/video/actearlycurriculum/index.html) are illustrative and promote understanding of the qualitative impairments of ASD, supplemented by the written text definitive criteria for ASD as outlined in the DSM-5 manual. 


\section{Primary care screening}

Primary care providers screen for ASDs for children 18 and 24 months of age based on American Academy of Pediatrics (AAP) guidelines (Council on Children With Disabilities, 2006, Johnson and Myers, 2007). Numerous screening tools specific to ASD symptoms are available (Council on Children With Disabilities, 2006, Gardner, 2012, Zwaigenbaum, 2011). A commonly used tool is the Modified Checklist for Autism in Toddlers Revised Form (Herlihy et al., 2014, Robins et al., 2014). Primary care providers refer children for expert diagnostic evaluations if they appear to be at risk for ASD, based on this preliminary screening tool. Box 2 lists absolute "red flags" that should prompt referral for further diagnostic evaluation for ASD. These red flags are generally accepted by developmental specialists and are consistent with the social communication and restricted and repetitive behavior hallmarks of ASD. For children with positive ASD screening results and clinician concern, timely referral to both a developmental clinic for further diagnostic evaluations and referral to community early intervention program should occur simultaneously (Gardner, 2012, Johnson and Myers, 2007, Manning-Courtney et al., 2013).

\section{Box 2}

Absolute indications for referral for autism spectrum disorder diagnostic evaluation No babbling by 12 months

No gesturing (e.g., pointing and waving bye-bye) by 12 months

No single words by 16 months

No two-word spontaneous (not echolalic) phrases by 24 months

Any loss of any language or social skills at any age

Note. Data from Filipek et al., 2000, Gardner, 2012, Johnson and Myers, 2007.

\section{Expert Diagnosis}

No medical or diagnostic markers exist to definitively diagnose ASD. The diagnostic process by experts involves comprehensive developmental screening by a multidisciplinary team of clinicians, including ASD-specific screening, which has been shown to be more reliable in detecting ASD than clinician observation alone (Daniels and Mandell, 2013, Guevara et al., 2013, Miller et al., 2011). The team evaluation consists of a developmental pediatric evaluation, administration of an ASD-specific diagnostic instrument, and a psychological evaluation. The developmental pediatric evaluation includes a detailed family, birth, medical, and developmental history, physical and neurologic examination, and developmental observations. The ASD-specific diagnostic instrument is the Autism Diagnostic Observation Schedule (ADOS), which is a standardized instrument that assesses social and communicative functions (Lord et al., 2012). Trained evaluators from any discipline such as speech and language, psychology, nursing, and education can administer the ADOS. The ASD-specific psychology evaluation includes standardized cognitive (intelligence quotient [IQ]), behavioral, emotional, and ASDspecific assessments.

Further medical evaluations are customized to the individual clinical situation. Because one early indicator of ASD is the inability of a child to orient to his or her name (Schaefer \& Mendelsohn, 2013), all children should have an audiogram to rule out hearing loss as part of the effort to secure an accurate diagnosis. Children with significant hearing loss may display socialization and communication 
difficulties and be misidentified as having ASD (Schaefer \& Mendelsohn, 2013). After an accurate diagnosis, the primary care medical home provider should refer the child for genetics evaluation because ASD is thought to have a genetic basis (Schaefer \& Mendelsohn, 2013).

\section{Genetic and Genomics of Autism}

The underlying cause of ASD and the subsequent challenging behaviors of children with ASD is the subject of much debate and research. It is commonly accepted that ASD is influenced by genetics (Buxbaum et al., 2014, Johnson et al., 2013b; Myers et al., 2011, Veenstra-Vanderweele et al., 2004), contributing factors in the environment (Shelton, Hertz-Picciotto, \& Pessah, 2012), and maternal immune-mediated responses (Lyall, Ashwood, Van de Water, \& Hertz-Picciotto, 2014). Researchers are studying several environmental factors that may affect gene expression and that also may modify gene expression via epigenetic changes (Shulha et al., 2012).

An international consortium of researchers has progressed in our understanding of ASD genetics by the use of candidate gene analysis, gene sequencing, and the study of copy number variants (CNVs; Buxbaum et al., 2014). Current research supports a major genetic contribution in children diagnosed with ASD in approximately $10 \%$ of children assessed by Fragile $X$ testing and chromosome microarray analysis (Buxbaum et al., 2014). Fragile $X$, a single gene disorder affecting intellectual ability, is the most common single known cause of ASD (Kidd et al., 2014). Chromosome microarray analysis is a test that detects deletion or duplications of stretches of deoxyribonucleic acid known as CNVs. Chromosome microarray analysis is increasingly recommended in autism spectrum disorders (Peters \& Pertile, 2014). Ongoing research seeks to determine new genetic biomarkers that measure the causes of ASD with more accuracy.

With the heterogeneity of ASD, it is difficult to tell how the genetic determinants affect socialization and behavior directly. Various models attempt to understand the connection of the ASD genotype to the phenotype. One model depicts ASD as a disturbance of physiological and behavioral rhythms that possibly affect the child's development of social communication impairments and repetitive behaviors and interests (Tordjman et al., 2015). For now, HCPs assess and treat the symptoms of the co-morbid conditions rather than treating ASD as a singular disorder. The identification of an underlying genetic disorder would help provide a unifying diagnosis for the child with ASD (Schaefer \& Mendelsohn, 2013). Many syndromes have an established documented association with ASD (Johnson et al., 2013b, Schaefer and Mendelsohn, 2013; see Table 1). For these syndromes, no further investigation of the cause of the ASD is needed (Schaefer \& Mendelsohn, 2013). There is no known cure for ASDs or consensus regarding the most effective intervention strategy (Myers \& Johnson, 2007). Evidence suggests that only a minority of children progress to the point where they do not meet ASD diagnostic criteria (Fein et al., 2013).

Table 1. Genetic disorders associated with autism spectrum disorder

\begin{tabular}{|l|l|l|l|}
\hline Disorder & Incidence & $\begin{array}{l}\text { \% Co-occurring } \\
\text { with ASD }\end{array}$ & Descriptions \\
\hline Fragile X & $\begin{array}{l}1 / 3,600 \\
\text { males; }\end{array}$ & $\begin{array}{l}15-30 \text { (Harris, } \\
2011)\end{array}$ & $\begin{array}{l}\text { Single gene disorder affecting intellectual } \\
\text { ability (Harris, 2011) }\end{array}$ \\
\hline
\end{tabular}




\begin{tabular}{|c|c|c|c|}
\hline & $\begin{array}{l}1 / 8,000 \\
\text { females }\end{array}$ & & \\
\hline Rett syndrome & $\begin{array}{l}1 / 10,000 \\
\text { females }\end{array}$ & $\begin{array}{l}\text { 25-40 (Harris, } \\
2011)\end{array}$ & $\begin{array}{l}\text { Regressive neurodevelopmental disorder of } \\
\text { speech and unusual hand movement (Neul } \\
\text { et al., 2010) }\end{array}$ \\
\hline Tuberous sclerosis & $1 / 6,000$ & $\begin{array}{l}\text { 25-60 (Harris, } \\
\text { 2011) }\end{array}$ & $\begin{array}{l}\text { Nonmalignant tumors primarily in the brain, } \\
\text { eyes, and heart }\end{array}$ \\
\hline Down syndrome & $1 / 691$ & $\begin{array}{l}40 \text { (Warner, } \\
\text { Moss, Smith, \& } \\
\text { Howlin, 2014) }\end{array}$ & $\begin{array}{l}\text { Low muscle tone, small stature; more } \\
\text { behavior problems than children with Down } \\
\text { syndrome only (Warner, Moss, Smith, \& } \\
\text { Howlin, 2014) }\end{array}$ \\
\hline
\end{tabular}

Note. ASD = autism spectrum disorder.

Data from Siegel \& Beaulieu, 2012.

\section{Interventions}

Two systematic reviews of therapies for persons with ASD have been performed-one for children up to 12 years old (Weitlauf et al., 2014) and one for children ages 12 to 18 years (Lounds Taylor et al., 2012). Both reviews address areas for medical, educational, and behavioral interventions that may be used as evidence for clinical guidelines. In the review for the children aged 12 to 18 years, only five studies on medications were available, most of which were poor quality, pointing to a need for more research for this age group (Lounds Taylor et al., 2012).

Families typically choose which interventions to use for their child (Karst \& Van Hecke, 2012) but tend to not have the time, resources, or expertise to consider all the options available (Stephenson, Carter, \& Kemp, 2012). The high cost and variability in public funding and insurance coverage for some ASD interventions and complicated step-by-step formats of some interventions limit their feasibility and accessibility. As a result, parents may choose diets or medications not proven to be effective simply because they are straightforward interventions available at home (Lord \& Bishop, 2010). Matson, Adams, Williams, and Rieske (2013) report that there is low parental adherence and compliance to medically prescribed treatments. In addition, parents may experience high levels of stress as a result of the child's challenging behaviors. This stress takes a toll on the health of parents and may lead them to delay seeking care for their child (Bekhet et al., 2012, Cantwell et al., 2014, Johnson et al., 2011, Kerfeld et al., 2011, Lovell et al., 2012).

Recent literature highlights the importance of collaboration between parents and HCPs, known as shared decision making (SDM), for treatment selection, rather than simply expecting parent and child adherence to treatment recommendations (Institute of Medicine, 2015, Strauss et al., 2015, U.S. Department of Health and Human Services, 2010). Caregivers of children with ASD report a lack of SDM, difficulty accessing services, poor care coordination, and adverse family experiences compared with caregivers of children with developmental disabilities, mental health conditions, or both (Carbone et al., 2010, Vohra et al., 2014). Two inherent issues exist: limited SDM for ASD, and, even when SDM is present, a lack of HCPs who understand the complexity of parenting a child with ASD (Bultas, 2012, Johnson et al., 2011). 


\section{Medical and Related Interventions}

Medical interventions target the symptoms of the developmental, psychiatric, neurologic, and gastrointestinal disorders that may co-occur with ASD (Levy et al., 2010). After receiving the medical diagnosis of ASD, children may be referred to specialists or an ASD center for ongoing developmental and medical follow up of co-occurring conditions. The focus in follow-up medical visits can often be problem-focused, reviewing with the family their day-to-day care of their child with ASD. As with many other chronic medical conditions, other medical problems can be seen that require acute episodic health care.

\section{Seizures}

Approximately $30 \%$ of children on the autism spectrum may have seizures sometime during their life (Tuchman, Moshe, \& Rapin, 2009). Andell and colleagues (2015) reported that the most common neurodevelopment comorbidities of children 0 to 18 years $(n=766)$ who had a new-onset unprovoked seizure were developmental delay (22\%; confidence interval $[\mathrm{Cl}], 19 \%$ to $25 \%$ ), speech/language and learning difficulties (23\%; $\mathrm{Cl}, 20 \%$ to $26 \%$ ), and intellectual disability (16\%; Cl, $13 \%$ to $18 \%$ ). Seizures were more common in older children with co-occurring psychiatric diagnosis (Andell et al., 2015). The onset of epilepsy peaks during adolescence and adulthood in ASD, for unknown reasons, and may be unique to children with ASD compared with other developmental disabilities (Tuchman et al., 2009).

\section{Gastrointestinal disturbances}

Research on specific gastrointestinal disorders that co-occur with ASD is limited. Gastrointestinal symptoms are difficult to evaluate because of the child's limited communication (Buie et al., 2010). Problem behavior in children with ASD may be the primary or sole symptom of an underlying gastrointestinal condition (Buie et al., 2010). Parents report that gastrointestinal issues are often the antecedent to challenging child behaviors and dysregulated sleep (Coury, Ashwood, et al., 2012). These conditions include gastroesophageal reflux disease, eosinophilic esophagitis, or and/or constipation (Coury, Ashwood, et al., 2012). Sensory integration differences may result in textural aversions to certain foods and a limited repertoire of food choices with a very selective diet (Badalyan and Schwartz, 2012, Chandler et al., 2013). The altered eating habits, along with psychopharmacological treatment, genetics, disordered sleep, and lack of adequate physical activity, contribute to the risk of obesity in this population (Curtin, Jojic, \& Bandini, 2014). Children with ASD have a higher prevalence of obesity than the general population (Curtin, Anderson, Must, \& Bandini, 2010).

Some parents of children with ASD try the gluten casein-free diet in an attempt to help improve their child's behavior. The diet is an exclusion diet that is costly and inconvenient. Evidence is lacking that following this diet improves a child's challenging behaviors and cognitive and social functioning (Millward, Ferriter, Calver, \& Connell-Jones, 2008). Furthermore, following a gluten casein-free diet may place children at risk for suboptimal bone development (Geraghty, Depasquale, \& Lane, 2010).

\section{Pain sensitivity}

In a systematic review of the pain of children with ASD, children with ASD were found to have different patterns of pain and discomfort expression than typically developing children. Instead of crying and seeking comfort, some children with ASD express pain differently (Allely, 2013). For example, some children with ASD who are in pain display the following: "furrowed brow," "banging his/her head," "injuring oneself," "grimacing," "guarding," and "increased heart rate" (Inglese, 2008). Other identified 
indicators of pain may be subjective and required (a) knowledge of the child's baseline and (b) monitoring for changes from normal (i.e., "crankiness," "being less active," "rocking unusually," "acting," "off," and "irritability"; Inglese, 2008). HCPs must be careful to not interpret this lack of typical finding as pain insensitivity or incorrectly assume that the child is in no pain (Allely, 2013). Close collaboration with parents to learn how their child expresses pain is indicated because some parents are able to describe unique behaviors that let them know when their child is in pain (Allely, 2013).

\section{Medication Management of Symptoms of ASD}

The use of medication in children with ASD is varied and usually symptom-specific. No medication has yet been developed that targets the core deficits seen in ASD-specifically, disordered language and social skill deficits. However, when concurrent medical symptoms are present, medications can be useful. The use of medication is carefully reviewed in the context of current health status and ongoing treatments. In determining a medication for behavior concerns, a careful history is needed to identify what may be triggering symptoms. For example, if anxiety seems to precede behavior outbursts, then anti-anxiety medication may be appropriate. The HCP should review with the family that the goal of medication treatment is to lessen the intensity of a symptom that may be interfering with the child's ability to make progress. Deciding to begin a medication is often a "try and see" or trial approach, with a "start low and go slow" format for making dose adjustments (Reinhold \& Manning-Courney, 2007).

Many children with ASD take psychotropic medications for challenging behaviors. In one study, Coury and colleagues determined the percentage of children with ASD ( $n=2,853$ children ages 3 to 17 years) who took at least one psychotropic medication by age range as follows: $11 \%$ of children aged 3 to 5 years; $46 \%$ of children aged 6 to 11 years; and 66\% of children aged 12 to 17 years (Coury, Anagnostou, et al., 2012). Thus more teenagers are medicated than are children. The number of clinical trials of psychotropic medications continues to increase, which is helpful in guiding clinical practice. Measuring outcomes in the use of these medications continues to be difficult. Additionally, many medications in current use are considered "off-label," without Food and Drug Administration (FDA) approval. However, avoiding agents that are off-label limits choices for potentially efficacious treatment. Currently, only two psychotropic medications, risperidone and aripiprazole, have FDA approval in the treatment of children with aggression and ASD (Weitlauf et al., 2014). Overall, medication combined with behavioral intervention appears to be more effective for reducing aggressive behavior than medication alone (Dawson \& Burner, 2011).

Many children with ASD take psychotropic medications for challenging behaviors.

Some children on the autism spectrum have significant inattention, distractibility, and/or hyperactive behavior. Stimulant medications such as methylphenidate (Ritalin) diminish impulsivity and hyperactivity by blocking the reuptake of catecholamine (norepinephrine and dopamine) at the synaptic cleft (Purper-Ouakil, Ramoz, Lepagnol-Bestel, Gorwood, \& Simonneau, 2011). Stimulants improve focus and decrease aggression for children with and without ADHD (Blader et al., 2013). Table 2 lists common problems and psychotropic medications used in the treatment of ASD.

Table 2. Co-occurring conditions, diagnostics, and medications for autism spectrum disorder

\begin{tabular}{|l|l|l|}
\hline Problem & Comments & Medications \\
\hline
\end{tabular}




\begin{tabular}{|c|c|c|}
\hline $\begin{array}{l}\text { Anxiety and } \\
\text { obsessive } \\
\text { compulsive } \\
\text { features }\end{array}$ & $\begin{array}{l}\text { Medications are not the first line of } \\
\text { treatment but may be helpful in } \\
\text { lowering anxiety } \\
\text { SSRI medications have not been } \\
\text { studied enough to know if they are } \\
\text { helpful for ASD symptoms } \\
\text { SSRIs carry a black box warning } \\
\text { Benzodiazepines are used with } \\
\text { caution because of the possibility of } \\
\text { paradoxical effect and/or tolerance }\end{array}$ & $\begin{array}{l}\text { SSRIs: citalopram, clomipramine, } \\
\text { desipramine, fluoxetine, fluvoxamine, } \\
\text { paroxetine, and sertraline; } \\
\text { An alternate anxiolytic, buspirone, has } \\
\text { been used as an add-on medication or } \\
\text { an alternative to the SSRI category }\end{array}$ \\
\hline $\begin{array}{l}\text { Hyperactivity, } \\
\text { distractibility, } \\
\text { or inattention }\end{array}$ & $\begin{array}{l}\text { Stimulant medications have not } \\
\text { been studied enough to know if they } \\
\text { are helpful for ASD symptoms } \\
\text { Atomoxetine cannot be crushed or } \\
\text { sprinkled and takes several weeks } \\
\text { for onset } \\
\text { Alpha } 2 \text { agonists (short and long } \\
\text { acting) have been used off label and } \\
\text { in younger children }\end{array}$ & $\begin{array}{l}\text { Stimulant: methylphenidate } \\
\text { Amphetamine and } \\
\text { dextroamphetamine: Adderall } \\
\text { Alpha-2 agonist: clonidine, guanfacine }\end{array}$ \\
\hline $\begin{array}{l}\text { Aggression, } \\
\text { agitation, self- } \\
\text { injurious behavior }\end{array}$ & $\begin{array}{l}\text { Only two medications approved for } \\
\text { the treatment of agitation and } \\
\text { aggression in children with ASD: } \\
\text { risperidone and aripiprazole } \\
\text { Antipsychotics associated with } \\
\text { weight gain, sleepiness, tremors and } \\
\text { abnormal movements } \\
\text { Antiepileptic medications have been } \\
\text { used to stabilize mood }\end{array}$ & $\begin{array}{l}\text { Antipsychotic agents: aripiprazole } \\
\text { chlorpromazine, clozapine, haloperidol, } \\
\text { olanzapine, perphenazine, risperidone, } \\
\text { and ziprasidone } \\
\text { Mood stabilizer: carbamazepine, } \\
\text { divalproex, lamotrigine, levetiracetam, } \\
\text { lithium, and oxcarbazepine }\end{array}$ \\
\hline Seizures & $\begin{array}{l}\text { 1. EEG studies recommended for } \\
\text { staring with unresponsiveness } \\
\text { 2. Neuroimaging studies } \\
\text { recommended if EEG abnormalities } \\
\text { are present }\end{array}$ & $\begin{array}{l}\text { Antiepileptic medications: lamotrigine, } \\
\text { oxcarbazepine, valproate }\end{array}$ \\
\hline
\end{tabular}

Note. $\mathrm{ASD}$ = autism spectrum disorder; $\mathrm{EEG}$ = electroencephalogram; SSRI = selective serotonin reuptake inhibitor.

Data from Siegel \& Beaulieu, 2012.

\section{Educational Intervention}

The Individuals with Disabilities Education Improvement Act (IDEIA) mandates that parents of children aged 3 to 21 years with ASD be actively involved in decisions about the services and accommodations for their child through SDM (U.S. Department of Education, 2015). According to IDEIA, state departments of instruction are mandated to identify students with ASD and provide services in special education programs in the local school district for those older than 3 years. For children younger than 3 years, early intervention services are available throughout the United States, based in state county 
programs (U.S. Department of Education, 2015). Some children may only be diagnosed with ASD as part of a school evaluation rather than a formal evaluation for ASD. An educational diagnosis of ASD is based on the criteria from IDEIA (IDEIA, 2004). This educational ASD diagnosis can be quite helpful in guiding the child's individualized educational plan.

Early intervention services must be provided in natural environments, including the home and community settings in which children without disabilities participate.

Early intervention services must be provided in natural environments, including the home and community settings in which children without disabilities participate. Parents of children with ASD are supported to help their children generalize skills learned at school into the home (Carter et al., 2013, Machalicek et al., 2008). Children receive other therapeutic interventions at school, such as speech and language therapy and occupational therapy for fine motor deficit and sensory integration difficulties (Weitlauf et al., 2014).

\section{Behavioral Interventions}

Numerous interventions have been designed to target the core features of ASD - that is, social communication and social interaction deficits and restricted, repetitive patterns of behavior, interests, or activities (see Table 3). Applied behavior analysis (ABA) is considered a best practice for the education of children with ASD, intellectual disability, and related disorders (Hagopian \& Hardesty, 2015). ABA was first defined in 1968 as the process of systematically applying interventions based upon the principles of learning theory directed at improving the behavior (Baer, Wolf, \& Risley, 1968).

Table 3. Select interventions for autism spectrum disorder

\begin{tabular}{|l|l|l|}
\hline Program & Select examples & Focus \\
\hline $\begin{array}{l}\text { Early intensive } \\
\text { behavioral } \\
\text { intervention }\end{array}$ & 1. Applied behavior analysis (Lovaas, 1987) & Overall development \\
\hline & 2. Early Start Denver (Dawson et al., 2010) & $\begin{array}{l}\text { Overall development, } \\
\text { core symptoms, adaptive } \\
\text { behavior }\end{array}$ \\
\hline & $\begin{array}{l}\text { 3. Pivotal response training (Koegel, Koegel, } \\
\text { Harrower, \& Carter, 1999) }\end{array}$ & Parent led, play based \\
\hline $\begin{array}{l}\text { 4. Floor time therapy derived from the } \\
\text { Developmental Individual-Difference } \\
\text { Relationship-based model (Wieder \& Greenspan, } \\
\text { 2003) } \\
\text { behavioral therapy }\end{array}$ & $\begin{array}{l}\text { 1. Coping Cat (McNally Keehn, Lincoln, Brown, \& } \\
\text { Chavira, 2013) }\end{array}$ & $\begin{array}{l}\text { Pelps high-functioning } \\
\text { lead }\end{array}$ \\
\hline $\begin{array}{l}\text { 2. Facing your fears (Reaven, Blakeley-Smith, } \\
\text { Leuthe, Moody, \& Hepburn, 2012) }\end{array}$ & $\begin{array}{l}\text { Helps high-functioning } \\
\text { children manage anxiety }\end{array}$ \\
\hline $\begin{array}{l}\text { Social skills } \\
\text { programs }\end{array}$ & $\begin{array}{l}\text { 1. Skill streaming (Goldstein \& McGinnis, 1997) } \\
\text { Social skills, attention, } \\
\text { play }\end{array}$ \\
\hline
\end{tabular}


2. Joint attention, symbolic play, engagement, and regulation (JASPER; Kasari, Gulsrud, Paparella, Hellemann, \& Berry, 2015)
Parent mediated for joint attention and cooperative play

ABA uses a behaviorist approach for either comprehensive or focused interventions (Hagopian \& Hardesty, 2015). Comprehensive interventions aim to improve skills that have an impact on global measures of functioning over time, such as IQ, language/communication, socialization, discrimination, and attention (Hagopian \& Hardesty, 2015). Small amounts of information are presented in repeated trials, using clear interactions, which are structured in a three-part contingency pattern (antecedentresponse-consequence; Weitlauf et al., 2014). Comprehensive ABA is generally home based for 25 to 40 hours/week for several years (Hagopian \& Hardesty, 2015). By contrast, focused interventions occur over a shorter amount of time. For example, a functional behavioral assessment to identify the variables antecedent to a problem behavior, such as aggression or self-injury, is considered a focused intervention (Hagopian \& Hardesty, 2015).

Scientific support during the past 40 years links ABA-based procedures with reduction of problem behaviors and increasing appropriate skills (Hagopian \& Hardesty, 2015). Research on children who received comprehensive ABA therapy for at least 8 months to 2 years showed greater improvements in cognitive performance, language skills, and adaptive behavior skills than broadly defined eclectic treatments available in the community (Weitlauf et al., 2014). A subset of all children who receive early intensive intervention showed significant improvement in terms of standardized outcomes, although many children continue to have substantial problems (Weitlauf et al., 2014). Research also shows promise for Naturalistic Developmental Behavioral Interventions (Schreibman et al., 2015), which use the principles of $A B A$ in settings that are naturalistic, such as home and with a different arrangement of the three-part contingency. For example, a child may be placed in an environment (e.g., the kitchen) where he or she has to initiate an interaction with someone (e.g., ask for an apple) to get a desired item (apple) (Schreibman et al., 2015).

Some evidence suggests that improvements with ABA may vary with the underlying severity of the disorder, but more research for the correlates of improvement is needed (Weitlauf et al., 2014). Future research needs to look at how family functioning affects outcomes of ABA therapy and include measures of parental well-being (Howlin, Magiati, \& Charman, 2009). Because family functioning affects child behaviors, all children who receive ABA therapy may not have acquired adequate adaptive behavior skills to cope with stressful acute episodic health care interactions. In an effort to help with family functioning, Autism Speaks has created tool kits with evidence-based guidance for parents with children with challenging behaviors (Autism Speaks, 2012) and ABA therapy (Autism Speaks, 2015). More information on the behavior management of children with ASD can be found in part 2 of this two-part publication on translating evidence to practice for children with ASD.

\section{Conclusion}

The research base representing the translation of evidence to practice for the health care of children with ASD is still a developing area of research. We presented background on the current state of the science related to ASD definition, associated behaviors, prevalence, diagnostic process, and 
interventions. This evidence can inform health care institution clinical guidelines and policies. Future research is needed to test interventions that decrease children's challenging behaviors and promote SDM among HCPs and families to optimize child and family health outcomes in health care settings.

\section{References}

Allely, 2013. C.S. Allely. Pain sensitivity and observer perception of pain in individuals with autistic spectrum disorder. Scientific World Journal, 2013 (2013), p. 916178

American Psychiatric Association, 1952. American Psychiatric Association. Diagnostic and statistical manual of mental disorders .(1st ed.), Author, Washington, DC (1952)

American Psychiatric Association, 1968. American Psychiatric Association. Diagnostic and statistical manual of mental disorders. (2nd ed.), Author, Washington, DC (1968)

American Psychiatric Association, 1980. American Psychiatric Association. Diagnostic and statistical manual of mental disorders. (3rd ed.), Author, Washington, DC (1980)

American Psychiatric Association, 1994. American Psychiatric Association. Diagnostic and statistical manual of mental disorders. (4th ed.), Author, Washington, DC (1994)

American Psychiatric Association, 2000. American Psychiatric Association. Diagnostic and statistical manual of mental disorders .(4th ed.), Author, Washington, DC (2000) text revision

American Psychiatric Association, 2013. American Psychiatric Association. Diagnostic and Statistical Manual of Mental Disorders. (5th ed.), American Psychiatric Publishing, Arlington, VA (2013)

Andell et al., 2015. E. Andell, T. Tomson, S. Carlsson, E. Hellebro, T. Andersson, C. Adelow, P. Amark. The incidence of unprovoked seizures and occurrence of neurodevelopmental comorbidities in children at the time of their first epileptic seizure and during the subsequent six months. Epilepsy Research, 113 (2015), pp. 140-150

Autism Speaks, 2012. Autism Speaks. Challenging behaviors tool kit. (2012) Retrieved from https://www.autismspeaks.org/family-services/tool-kits/challenging-behaviors-tool-kit

Autism Speaks, 2015. Autism Speaks. ATN/AIR parent's guide to applied behavior analysis. (2015) Retrieved from https://www.autismspeaks.org/science/resources-programs/autism-treatmentnetwork/atn-air-p-applied-behavior-analysis

Badalyan and Schwartz, 2012. V. Badalyan, R.H. Schwartz. Mealtime feeding behaviors and gastrointestinal dysfunction in children with classic autism compared with normal sibling controls. Open Journal of Pediatrics, 2 (2) (2012), pp. 150-160

Baer et al., 1968. D.M. Baer, M.M. Wolf, T.R. Risley. Some current dimensions of applied behavior analysis. Journal of Applied Behavior Analysis, 1 (1968), pp. 91-97

Baio et al., 2014. J. Baio, M. Wingate, R.S. Kirby, S. Pettygrove, C. Cunniff, E. Schulz, T. Ghosh. Prevalence of autism spectrum disorder among children aged 8 years-Autism and Developmental Disabilities Monitoring Network, 11 sites, United States, 2010. MMWR: Morbidity \& Mortality Weekly Report, 63 (2) (2014), pp. 1-21

Bekhet et al., 2012. A.K. Bekhet, N.L. Johnson, J. Zauszniewski. Resilience in family members of persons with autism spectrum disorder: a review of the literature. Issues in Mental Health Nursing, 33 (10) (2012), pp. 650-656

Blader et al., 2013. J.C. Blader, S.R. Pliszka, V. Kafantaris, C.A. Foley, J.A. Crowell, G.A. Carlson, et al., W.B. Daviss. Callous-unemotional traits, proactive aggression, and treatment outcomes of aggressive children with attention-deficit/hyperactivity disorder. Journal of the American Academy of Child Adolescent Psychiatry, 52 (e12) (2013), pp. 1281-1293 
Buie et al., 2010. T. Buie, G.J. Fuchs 3rd, G.T. Furuta, K. Kooros, J. Levy, J.D. Lewis, et al., H. Winter. Recommendations for evaluation and treatment of common gastrointestinal problems in children with ASDs. Pediatrics, 125 (suppl. 1) (2010), pp. S19-S29

Bultas, 2012. M.W. Bultas. The health care experiences of the preschool child with autism. Journal of Pediatric Nursing, 27 (5) (2012), pp. 460-470

Burkett et al., 2015. K. Burkett, E. Morris, P. Manning-Courtney, J. Anthony, D. Shambley-Ebron. African American families on autism diagnosis and treatment: the influence of culture. Journal of Autism and Developmental Disorders, 45 (10) (2015), pp. 3244-3254

Burkett and Morris, 2015. K.W. Burkett, E.J. Morris. Enabling trust in qualitative research with culturally diverse participants. Journal of Pediatric Health Care, 29 (1) (2015), pp. 108-112

Buxbaum et al., 2014. J.D. Buxbaum, N. Bolshakova, J.M. Brownfeld, R.J. Anney, P. Bender, R. Bernier, et al., L. Gallagher. The Autism Simplex Collection: An international, expertly phenotyped autism sample for genetic and phenotypic analyses. Molecular Autism, 5 (2014), p. 34

Cantwell et al., 2014. J. Cantwell, O.T. Muldoon, S. Gallagher. Social support and mastery influence the association between stress and poor physical health in parents caring for children with developmental disabilities. Research Developmental Disabilities, 35 (9) (2014), pp. 2215-2223

Carbone et al., 2010. P. Carbone, D. Behl, V. Azor, N. Murphy. The medical home for children with autism spectrum disorders: Parent and pediatrician perspectives. Journal of Autism \& Developmental Disorders, 40 (2010), pp. 317-324

Carter et al., 2013. E.W. Carter, K.L. Lane, M. Cooney, K. Weir, C.K. Moss, W. Machalicek. Parent assessments of self-determination importance and performance for students with autism or intellectual disability. American Journal on Intellectual and Developmental Disabilities, 118 (1) (2013), pp. 16-31

Chandler et al., 2013. S. Chandler, I. Carcani-Rathwell, T. Charman, A. Pickles, T. Loucas, D. Meldrum, et al., G. Baird. Parent-reported gastro-intestinal symptoms in children with autism spectrum disorders. Journal of Autism and Developmental Disorders, 43 (12) (2013), pp. 2737-2747

Council on Children With Disabilities, 2006. Council on Children With Disabilities. Identifying infants and young children with developmental disorders in the medical home: An algorithm for developmental surveillance and screening. Pediatrics, 118 (1) (2006), pp. 405-420

Coury et al., 2012a. D.L. Coury, E. Anagnostou, P. Manning-Courtney, A. Reynolds, L. Cole, R. McCoy, et al., J.M. Perrin. Use of psychotropic medication in children and adolescents with autism spectrum disorders. Pediatrics, 130 (suppl. 2) (2012), pp. S69-S76

Coury et al., 2012b. D.L. Coury, P. Ashwood, A. Fasano, G. Fuchs, M. Geraghty, A. Kaul, et al., N.E. Jones. Gastrointestinal conditions in children with autism spectrum disorder: Developing a research agenda. Pediatrics, 130 (suppl 2) (2012), pp. S160-S168

Curtin et al., 2010. C. Curtin, S.E. Anderson, A. Must, L. Bandini. The prevalence of obesity in children with autism: A secondary data analysis using nationally representative data from the National Survey of Children's Health. BMC Pediatric, 10 (2010), p. 11

Curtin et al., 2014. C. Curtin, M. Jojic, L.G. Bandini. Obesity in children with autism spectrum disorder. Harvard Review of Psychiatry, 22 (2) (2014), pp. 93-103

Daniel et al., 2009. K.L. Daniel, C. Prue, M.K. Taylor, J. Thomas, M. Scales. 'Learn the signs. Act early': A campaign to help every child reach his or her full potential. Public Health, 123 (suppl. 1) (2009), pp. e11-e16

Daniels and Mandell, 2013. A.M. Daniels, D. Mandell. Children's compliance with American Academy of Pediatrics well-child care visit guidelines and the early detection of autism. Journal of Autism \& Developmental Disorders, 43 (12) (2013), pp. 2844-2854 
Davis et al., 2010. T.E. Davis, J.C. Fodstad, W.S. Jenkins, J.A. Hess, B.N. Moree, T. Dempsey, J.L. Matson. Anxiety and avoidance in infants and toddlers with autism spectrum disorders: Evidence for differing symptom severity and presentation. Research in Autism Spectrum Disorders, 4 (2) (2010), pp. 305-313

Davis et al., 2011. T.E. Davis, B.N. Moree, T. Dempsey, E.T. Reuther, J.C. Fodstad, J.A. Hess, et al., J.L. Matson. The relationship between autism spectrum disorders and anxiety: The moderating effect of communication. Research in Autism Spectrum Disorders, 5 (1) (2011), pp. 324-329

Dawson and Burner, 2011. G. Dawson, K. Burner. Behavioral interventions in children and adolescents with autism spectrum disorder: A review of recent findings. Current Opinion in Pediatrics, 23 (6) (2011), pp. 616-620

Dawson et al., 2010. G. Dawson, S. Rogers, J. Munson, M. Smith, J. Winter, J. Greenson, et al., J. Varley. Randomized, controlled trial of an intervention for toddlers with autism: The Early Start Denver Model. Pediatrics, 125 (1) (2010), pp. e17-e23

Fein et al., 2013. D. Fein, M. Barton, I.M. Eigsti, E. Kelley, L. Naigles, R.T. Schultz, et al., K. Tyson. Optimal outcome in individuals with a history of autism. Journal of Child Psychology and Psychiatry, 54 (2) (2013), pp. 195-205

Filipek et al., 2000. P. Filipek, P. Accardo, S. Ashwal, G. Baranek, E. Cook, G. Dawson, et al., F. Volkmar. Practice parameter: Screening and diagnosis of autism - report of the Quality Standards Subcommittee of the American Academy of Neurology and the Child Neurology Society. Neurology, 55 (2000), pp. 468-479

Fombonne, 2009. E. Fombonne. Epidemiology of pervasive developmental disorders. Pediatric Research, 65 (2009), pp. 591-598

Gardner, 2012. M. Gardner. Finding what we're looking for: Evidence-based early identification and nursing care of young children at risk for autism spectrum disorders. E. Giarelli, M. Gardner (Eds.), Nursing of autism spectrum disorder: Evidence-based integrated care across the lifespan, Springer, New York, NY (2012)

Geraghty et al., 2010. M.E. Geraghty, G.M. Depasquale, A.E. Lane. Nutritional intake and therapies in autism: A spectrum of what we know: Part 1. ICAN: Infant, Child, \& Adolescent Nutrition, 2 (1) (2010), pp. 62-69

Goldstein and McGinnis, 1997. A. Goldstein, A. McGinnis. Skillstreaming the adolescent: New strategies \& perspectives for teaching prosocial skills (revised edition). Research Press, Champaign, IL (1997)

Guevara et al., 2013. J.P. Guevara, M. Gerdes, R. Localio, V.H. Yuanshung, J. Pinto-Martin, C.S. Minkovitz, et al., S. Pati. Effectiveness of developmental screening in an urban setting. Pediatrics, 131 (1) (2013), pp. 30-37

Hagopian and Hardesty, 2015. L.P. Hagopian, S.L. Hardesty. Overview and summary of scientific support for applied behavior analysis. (2015) Retrieved from http://www.kennedykrieger.org/sites/kki2.com/files/aba-scientific-support.pdf

Hall, 2012. H.R. Hall. Families of children with autism: behaviors of children, community support and coping. Issues in Comprehensive Pediatric Nursing, 35 (2) (2012), pp. 111-132

Harris 2011. J.C. Harris. Autism spectrum diagnoses in neurogenetic syndromes. E. Hollander, V. Kolevzon, J.T. Coyle (Eds.), Textbook of autism spectrum disorders, American Psychiatric Publishing Co, Washington, DC (2011), pp. 223-235

Herlihy et al., 2014. L.E. Herlihy, B. Brooks, T. Dumont-Mathieu, M.L. Barton, D. Fein, C.M. Chen, D.L. Robins. Standardized screening facilitates timely diagnosis of autism spectrum disorders in a 
diverse sample of low-risk toddlers. Journal of Developmental and Behavioral Pediatrics, 35 (2) (2014), pp. 85-92

Howlin et al., 2009. P. Howlin, I. Magiati, T. Charman. Systematic review of early intensive behavioral interventions for children with autism. American Journal on Intellectual and Developmental Disabilities, 114 (1) (2009), pp. 23-41

Individuals with Disabilities Educational Improvement Act (IDEIA) 2004. Individuals with Disabilities Educational Improvement Act (IDEIA). Sec. 300.8 Child with a disability. (2004) Retrieved from http://idea.ed.gov/download/statute.html

Inglese, 2008. M.D. Inglese. Pain expression in children with autism spectrum disorder (ASD), A foundation for instrument development (unpublished doctoral dissertation). The University of Florida, Gainesville, FL (2008)

Institute of Medicine, 2015. Institute of Medicine. Report brief: Vital signs core metrics for health and health care progress. (2015) Retrieved from http://www.iom.edu/Reports/2015/Vital-SignsCore-Metrics.aspx

Jarquin et al., 2011. V.G. Jarquin, L.D. Wiggins, L.A. Schieve, K. Van Naarden-Braun. Racial disparities in community identification of autism spectrum disorders over time; Metropolitan Atlanta, Georgia, 2000-2006. Journal of Developmental and Behavioral Pediatrics, 32 (3) (2011), pp. 179-187

Johnson and Myers, 2007. C.P. Johnson, S.M. Myers. American Academy of Pediatrics Council on Children with Disabilities: Identification and evaluation of children with autism spectrum disorders. Pediatrics, 120 (2007), pp. 1183-1215

Johnson and Rodriguez, 2013. N. Johnson, D. Rodriguez. Children with autism spectrum disorder at a pediatric hospital: A systematic review of the literature. Pediatric Nursing, 39 (3) (2013), pp. 131-141

Johnson et al., 2014. N.L. Johnson, A. Bekhet, K. Robinson, D. Rodriguez. Attributed meanings and strategies to prevent challenging behaviors of hospitalized children with autism: Two perspectives. Journal of Pediatric Health Care, 28 (5) (2014), pp. 386-393

Johnson et al., 2011. N.L. Johnson, M. Frenn, S. Feetham, P. Simpson. Autism spectrum disorder: Parenting stress, family functioning and health related quality of life. Family, Systems \& Health, 29 (3) (2011), pp. 232-252

Johnson et al., 2013b. N.L. Johnson, E. Giarelli, C. Lewis, C.E. Rice. Genomics and autism spectrum disorder. Journal of Nursing Scholarship, 45 (1) (2013), pp. 69-78

Karst and Van Hecke, 2012. J. Karst, A. Van Hecke. Parent and family impact of autism spectrum disorders: A review and proposed model for intervention evaluation. Clinical Child \& Family Psychology Review, 15 (3) (2012), pp. 247-277

Kasari et al., 2015. C. Kasari, A. Gulsrud, T. Paparella, G. Hellemann, K. Berry. Randomized comparative efficacy study of parent-mediated interventions for toddlers with autism. Journal of Consulting and Clinical Psychology, 83 (3) (2015), pp. 554-563

Kerfeld et al., 2011. C.I. Kerfeld, J.M. Hoffman, M.A. Ciol, D. Kartin. Delayed or forgone care and dissatisfaction with care for children with special health care needs: the role of perceived cultural competency of health care providers. Maternal Child Health Journal, 15 (4) (2011), pp. 487-496

Kidd et al., 2014. S.A. Kidd, A. Lachiewicz, D. Barbouth, R.K. Blitz, C. Delahunty, D. McBrien, et al., E. Berry-Kravis. Fragile $X$ syndrome: A review of associated medical problems. Pediatrics, 134 (5) (2014), pp. 995-1005 
Koegel et al., 1999. L.K. Koegel, R.L. Koegel, J.K. Harrower, C.M. Carter. Pivotal response intervention I: Overview of approach. Research and Practice for Persons with Severe Disabilities, 24 (3) (1999), pp. 174-185

Levy et al., 2010. S.E. Levy, E. Giarelli, L.C. Lee, L.A. Schieve, R.S. Kirby, C. Cunniff, et al., C.E. Rice. Autism spectrum disorder and co-occurring developmental, psychiatric, and medical conditions among children in multiple populations of the United States. Journal of Developmental Behavioral Pediatrics, 4 (2010), pp. 267-275

Lord and Bishop, 2010. C. Lord, S.L. Bishop. Autism spectrum disorders: Diagnosis, prevalence, and services for children and families. Social Policy Report, 24 (2) (2010), pp. 3-21

Lord et al., 2012. C. Lord, M. Rutter, P.C. DiLavore, S. Risi, K. Gotham, S.L. Bishop, et al., W. Guthrie. Autism diagnostic observation schedule. (2nd ed.) (2012) Retrieved from http://www.wpspublish.com/store/p/2648/autism-diagnostic-observation-schedule-secondedition-ados-2

Lounds Taylor et al., 2012. J. Lounds Taylor, D. Dove, J. Veenstra-VanderWeele, N.A. Sathe, M.L. McPheeters, R.N. Jerome, Z. Warren. Interventions for adolescents and young adults with autism spectrum disorders. Comparative Effectiveness Review No. 65. (Prepared by the Vanderbilt Evidence-based Practice Center under Contract No. 290-2007-10065-I.) AHRQ Publication No. 12-EHC063-EF. Agency for Healthcare Research and Quality, Rockville, MD (2012) August 2012. Retrieved from http://www.effectivehealthcare.ahrq.gov/search-forguides-reviews-and-reports/?pageaction=displayproduct\&productid=1197

Lovaas, 1987. O.I. Lovaas. Behavioral treatment and normal educational and intellectual functioning in young autistic children. Journal of Consulting and Clinical Psychology, 55 (1) (1987), pp. 3-9

Lovell et al., 2012. B. Lovell, M. Moss, M. Wetherell. The psychosocial, endocrine and immune consequences of caring for a child with autism or ADHD. Psychoneuroendocrinology, 37 (4) (2012), pp. 534-542

Lyall et al., 2014. K. Lyall, P. Ashwood, J. Van de Water, I. Hertz-Picciotto. Maternal immune-mediated conditions, autism spectrum disorders, and developmental delay. Journal of Autism and Developmental Disorders, 44 (7) (2014), pp. 1546-1555

Machalicek et al., 2008. W. Machalicek, M.F. O'Reilly, N. Beretvas, J. Sigafoos, G. Lancioni, A. Sorrells, et al., M. Rispoli. A review of school-based instructional interventions for students with autism spectrum disorders. Research in Autism Spectrum Disorders, 2 (3) (2008), pp. 395-416

Mandell et al., 2007. D. Mandell, R.F. Ittenbach, S.E. Levy, J.A. Pinto-Martin. Disparities in diagnoses received prior to a diagnosis of autism spectrum disorder. Journal of Autism \& Developmental Disorders, 37 (9) (2007), pp. 1795-1802

Mandell et al., 2002. D. Mandell, J. Listerud, S.E. Levy, J.A. Pinto-Martin. Race differences in the age at diagnosis among Medicaid-eligible children with autism. Journal of the American Academy of Child and Adolescent Psychiatry, 41 (12) (2002), pp. 1447-1453

Mandell et al., 2009. D. Mandell, L.D. Wiggins, L.A. Carpenter, J. Daniels, C. DiGuiseppi, M.S. Durkin, et al., R.S. Kirby. Racial/ethnic disparities in the identification of children with autism spectrum disorders. American Journal of Public Health, 99 (3) (2009), pp. 493-498

Manning-Courtney et al., 2013. P. Manning-Courtney, D. Murray, K. Currans, H. Johnson, N. Bing, K. Kroeger-Geoppinger, et al., T. Messerschmidt. Autism spectrum disorders. Current Problems in Pediatric and Adolescent Health Care, 43 (1) (2013), pp. 2-11

Matson et al., 2013. J. Matson, H.L. Adams, L.W. Williams, R.D. Rieske. Why are there so many unsubstantiated treatments in autism? Research in Autism Spectrum Disorders, 7 (2013), pp. 466-474 
Matson et al., 2011. J.L. Matson, M. Sipes, M. Horovitz, J.A. Worley, M.E. Shoemaker, A.M. Kozlowski.

Behaviors and corresponding functions addressed via functional assessment. Research in

Developmental Disabilities, 32 (2011), pp. 625-629

McNally Keehn et al., 2013. R.H. McNally Keehn, A.J. Lincoln, M.Z. Brown, D.A. Chavira. The Coping Cat program for children with anxiety and autism spectrum disorder: A pilot randomized controlled trial. Journal of Autism and Developmental Disorders, 43 (1) (2013), pp. 57-67

Miles, 2011. J.H. Miles. Autism spectrum disorders-a genetics review. Genetics in Medicine, 13 (4) (2011), pp. 278-294

Miller et al., 2011. J.S. Miller, T. Gabrielsen, M. Villalobos, R. Alleman, N. Wahmhoff, P.S. Carbone, B.

Segura. The Each Child Study: Systematic screening for autism spectrum disorders in a pediatric setting. Pediatrics, 127 (5) (2011), pp. 866-871

Millward et al., 2008. C. Millward, M. Ferriter, S. Calver, G. Connell-Jones. Gluten-and casein-free diets for autistic spectrum disorder. Cochrane Database Systematic Reviews, 2 (2) (2008), p. CD003498

Myers et al., 2011. R.A. Myers, F. Casals, J. Gauthier, F.F. Hamdan, J. Keebler, A.R. Boyko, et al., P. Awadalla. A population genetic approach to mapping neurological disorder genes using deep resequencing. PLoS Genetics, 7 (2) (2011), p. e1001318

Myers and Johnson, 2007. S.M. Myers, C.P. Johnson. Management of children with autism spectrum disorders. Pediatrics, 120 (5) (2007), pp. 1162-1182

Neul et al., 2010. J.L. Neul, W.E. Kaufmann, D.G. Glaze, J. Christodoulou, A.J. Clarke, N. Bahi-Buisson, et al., RettSearch Consortium. Rett syndrome: Revised diagnostic criteria and nomencloture. Annals of Neurology, 68 (6) (2010), pp. 944-950

Peters and Pertile, 2014. G.B. Peters, M.D. Pertile. Chromosome microarrays in diagnostic testing: Interpreting the genomic data. Methods in Molecular Biology, 1168 (2014), pp. 117-155

Purper-Ouakil et al., 2011. D. Purper-Ouakil, N. Ramoz, A.M. Lepagnol-Bestel, P. Gorwood, M. Simonneau. Neurobiology of attention deficit/hyperactivity disorder. Pediatric Research, 69 (5 Pt 2) (2011), pp. 69R-76R

Reaven et al., 2012. J. Reaven, A. Blakeley-Smith, E. Leuthe, E. Moody, S. Hepburn. Facing your fears in adolescence: Cognitive-behavioral therapy for high-functioning autism spectrum disorders and anxiety. Autism Research and Treatment, 2012 (2012), p. 423905

Reinhold and Manning-Courney, 2007. J.A. Reinhold, P. Manning-Courney. Medications used in the treatment of children with autism spectrum disorders. International Journal of Nursing in Intellectual and Developmental Disabilities, 3 (1) (2007) Retrieved from http://ddna.org/publications/journal/vol-3-issue-1-article-2/

Robins et al., 2014. D.L. Robins, K. Casagrande, M. Barton, C.M. Chen, T. Dumont-Mathieu, D. Fein. Validation of the modified checklist for autism in toddlers, revised with follow-up (M-CHATR/F). Pediatrics, 133 (1) (2014), pp. 37-45

Rutter, 2007. M. Rutter. Incidence of autism spectrum disorders: Changes over time and their meaning. Acta Paediatrica, 94 (1) (2007), pp. 2-15

Schaefer and Mendelsohn, 2013. G.B. Schaefer, N.J. Mendelsohn. MCMG practice guidelines: Clinical genetics evaluation in identifying the etiology of autism spectrum disorders: $\mathbf{2 0 1 3}$ guideline revisions. Genetics in Medicine, 15 (5) (2013), pp. 399-407

Schreibman et al., 2015. L. Schreibman, G. Dawson, A.C. Stahmer, R. Landa, S.J. Rogers, G.G. McGee, et al., A. Halladay. Naturalistic developmental behavioral interventions: Empirically validated treatments for autism spectrum disorder. Journal of Autism and Developmental Disorders, 45 (8) (2015), pp. 2411-2428 
Shelton et al., 2012. J.F. Shelton, I. Hertz-Picciotto, I.N. Pessah. Tipping the balance of autism risk:

Potential mechanisms linking pesticides and autism. Environmental Health Perspectives, 120

(7) (2012), pp. 944-951

Shulha et al., 2012. H.P. Shulha, I. Cheung, C. Whittle, J. Wang, D. Virgil, C.L. Lin, et al., S. Akbarian.

Epigenetic signatures of autism: Trimethylated H3K4 landscapes in prefrontal neurons.

Archives of General Psychiatry, 69 (3) (2012), pp. 314-324

Siegel, M.,et al., 2012. M. Siegel, A.A. Beaulieu. Psychotropic medications in children with autism spectrum disorders: a systematic review and synthesis for evidence-based practice. Journal of Autism and Developmental Disorders, 42 (8) (2012), pp. 1592-1605

Stephenson et al., 2012. J. Stephenson, M. Carter, C. Kemp. Quality of the information on educational and therapy interventions provided on the web sites of national autism associations.

Research in Autism Spectrum Disorders, 6 (1) (2012), pp. 11-18

Strauss et al., 2015. K. Strauss, A. Benvenuto, B. Battan, M. Siracusano, M. Terribili, P. Curatolo, L. Fava.

Promoting shared decision making to strengthen outcome of young children with autism spectrum disorders: The role of staff competence. Research in Developmental Disabilities, 38 (2015), pp. 48-63

Swineford et al., 2014. L.B. Swineford, A. Thurm, G. Baird, A.M. Wetherby, S. Swedo. Social (pragmatic) communication disorder: A research review of this new DSM-5 diagnostic category. Journal of Neurodevelopmental Disorders, 6 (1) (2014), p. 41

Tordjman et al., 2015. S. Tordjman, K.S. Davlantis, N. Georgieff, M.M. Geoffray, M. Speranza, G.M. Anderson, et al., G. Dawson. Autism as a disorder of biological and behavioral rhythms:

Toward new therapeutic perspectives. Frontiers in Pediatrics, 3 (2015), p. 1

Tuchman et al., 2009. R. Tuchman, S.L. Moshe, I. Rapin. Convulsing toward the pathophysiology of autism. Brain Development, 31 (2) (2009), pp. 95-103

U.S. Department of Education, 2015. U.S. Department of Education. Building the legacy: IDEA 2004. (2015) Retrieved from idea.ed.gov

U.S. Department of Health and Human Services, 2010. U.S. Department of Health and Human Services. The Affordable Care Act. (2010) Retrieved from http://www.hhs.gov/healthcare/rights/law/index.html

Valicenti-McDermott et al., 2012. M. Valicenti-McDermott, K. Hottinger, R. Seijo, L. Shulman. Age at diagnosis of autism spectrum disorders. Journal of Pediatrics, 161 (3) (2012), pp. 554-556

Veenstra-Vanderweele et al., 2004. J. Veenstra-Vanderweele, S. Christian, E.J. Cook. Autism as a paradigmatic complex genetic disorder. Annual Review of Genomics and Human Genetics, 5 (2004), pp. 379-405

Vohra et al., 2014. R. Vohra, S. Madhavan, U. Sambamoorthi, C. St Peter. Access to services, quality of care, and family impact for children with autism, other developmental disabilities, and other mental health conditions. Autism, 18 (7) (2014), pp. 815-826

Warner et al., 2014. G. Warner, J. Moss, P. Smith, P. Howlin. Autism characteristics and behavioural disturbances in $\sim \mathbf{5 0 0}$ children with Down's syndrome in England and Wales. Autism Research, 7 (4) (2014), pp. 433-441

Warren et al., 2011. Z. Warren, J. Veenstra-VanderWeele, W. Stone, J.L. Bruzek, A.S. Nahmias, J.H. Foss-Feig, et al., M.L. McPheeters. Therapies for children with autism spectrum disorders. Comparative Effectiveness Review No. 26. (Prepared by the Vanderbilt Evidence-based Practice Center under Contract No. 290-2007-10065-I.) AHRQ Publication No. 11-EHC029-EF. Agency for Healthcare Research and Quality, Rockville, MD (2011) April 2011. Retrieved from 
http://0-

www.ncbi.nlm.nih.gov.libus.csd.mu.edu/pubmedhealth/PMH0015709/?report=printable

Weitlauf et al., 2014. A. Weitlauf, M. McPheeters, B. Peters, N. Sathe, R. Travis, R. Aiello, et al., Z. Warren. Therapies for Children With Autism Spectrum Disorder: Behavioral Interventions Update. Comparative Effectiveness Review No. 137. (Prepared by the Vanderbilt Evidencebased Practice Center under Contract No. 290-2012-00009-I.)AHRQ Publication No. 14EHC036-EF. Agency for Healthcare Research and Quality, Rockville, MD (2014) August 2014. Retrieved from http://www.effectivehealthcare.ahrq.gov/search-for-guides-reviews-andreports/?pageaction=displayproduct \&productid=1946

Wieder and Greenspan, 2003. S. Wieder, S.I. Greenspan. Climbing the symbolic ladder in the DIR model through floor time/interactive play. Autism, 7 (4) (2003), pp. 425-435

Zuckerman et al., 2014. K.E. Zuckerman, B. Sinche, M. Cobian, M. Cervantes, A. Mejia, T. Becker, C. Nicolaidis. Conceptualization of autism in the Latino community and its relationship with early diagnosis. Journal of Developmental and Behavioral Pediatrics, 35 (8) (2014), pp. 522-532

Zwaigenbaum, 2011. L. Zwaigenbaum. Screening, risk, and early identification of autism spectrum disorders. D.G. Amaral, G. Dawson, D. Geschwind (Eds.), Autism spectrum disorders, Oxford University, New York, NY (2011), pp. 75-89 